\title{
Article \\ Effect of High-Protein Diets on Integrated Myofibrillar Protein Synthesis before Anterior Cruciate Ligament Reconstruction: A Randomized Controlled Pilot Study
}

\author{
Emily E. Howard 1,2,3 ${ }^{\mathbb{D}}$, Lee M. Margolis ${ }^{2}$, Maya A. Fussell ${ }^{1}$, Clifford G. Rios ${ }^{4}$, Eric M. Meisterling ${ }^{5}$, \\ Christopher J. Lena ${ }^{4}$, Stefan M. Pasiakos ${ }^{6}$ and Nancy R. Rodriguez ${ }^{1, *}$
}

1 Department of Nutritional Sciences, University of Connecticut, Storrs, CT 06269, USA; emily.e.howard14.civ@mail.mil (E.E.H.); maya.fussell@uconn.edu (M.A.F.)

2 Military Nutrition Division, United States Army Research Institute of Environmental Medicine, Natick, MA 01760, USA; lee.m.margolis.civ@mail.mil

3 Oak Ridge Institute for Science and Education, Oak Ridge, TN 37830, USA

4 Orthopedic Associates of Hartford Surgery Center, Glastonbury, CT 06033, USA; crios@oahctmd.com (C.G.R.); clena@oahctmd.com (C.J.L.)

5 Integrated Anesthesia Associates, Hartford, CT 06106, USA; emmmd@reagan.com

6 Military Performance Division, United States Army Research Institute of Environmental Medicine, Natick, MA 01760, USA; stefan.m.pasiakos.civ@mail.mil

* Correspondence: nancy.rodriguez@uconn.edu; Tel.: +1-(860)-486-0120

Citation: Howard, E.E.; Margolis, L.M.; Fussell, M.A.; Rios, C.G.;

Meisterling, E.M.; Lena, C.J.;

Pasiakos, S.M.; Rodriguez, N.R. Effect of High-Protein Diets on Integrated Myofibrillar Protein Synthesis before Anterior Cruciate Ligament Reconstruction: A Randomized Controlled Pilot Study. Nutrients 2022, 14, 563. https://doi.org/10.3390/nu14030563 Academic Editor: Louise Deldicque Received: 22 December 2021 Accepted: 25 January 2022 Published: 27 January 2022

Publisher's Note: MDPI stays neutral with regard to jurisdictional claims in published maps and institutional affiliations.

Copyright: (C) 2022 by the authors. Licensee MDPI, Basel, Switzerland. This article is an open access article distributed under the terms and conditions of the Creative Commons Attribution (CC BY) license (https:// creativecommons.org/licenses/by/ $4.0 /)$.

\begin{abstract}
Increasing dietary protein intake during periods of muscle disuse may mitigate the resulting decline in muscle protein synthesis (MPS). The purpose of this randomized pilot study was to determine the effect of increased protein intake during periods of disuse before anterior cruciate ligament (ACL) reconstruction on myofibrillar protein synthesis (MyoPS), and proteolytic and myogenic gene expression. Six healthy, young males $(30 \pm 9$ y) were randomized to consume a high-quality, optimal protein diet $\left(\mathrm{OP} ; 1.9 \mathrm{~g} \cdot \mathrm{kg}^{-1} \cdot \mathrm{d}^{-1}\right)$ or adequate protein diet $\left(\mathrm{AP} ; 1.2 \mathrm{~g} \cdot \mathrm{kg}^{-1} \cdot \mathrm{d}^{-1}\right)$ for two weeks before ACL reconstruction. Muscle biopsies collected during surgery were used to measure integrated MyoPS during the intervention (via daily deuterium oxide ingestion) and gene expression at the time of surgery. MyoPS tended to be higher, with a large effect size in OP compared to AP $\left(0.71 \pm 0.1\right.$ and $\left.0.54 \pm 0.1 \% \cdot \mathrm{d}^{-1} ; p=0.076 ; g=1.56\right)$. Markers of proteolysis and myogenesis were not different between groups $(p>0.05)$; however, participants with greater MyoPS exhibited lower levels of MuRF1 gene expression compared to those with lower MyoPS ( $\mathrm{r}=-0.82, p=0.047)$. The data from this pilot study reveal a potential stimulatory effect of increased daily protein intake on MyoPS during injury-mediated disuse conditions that warrants further investigation.
\end{abstract}

Keywords: muscle protein synthesis; disuse atrophy; musculoskeletal injury; anabolic resistance

\section{Introduction}

Muscle atrophy and weakness are well-recognized clinical outcomes of anterior cruciate ligament (ACL) injury and reconstructive surgery that can persist postoperatively despite aggressive physical rehabilitation efforts [1,2]. Muscle atrophy under these conditions results, in part, from knee joint trauma and associated deficits in neuromuscular signaling. Injury-related effusion, inflammation, pain, and damage to articular sensory receptors in the knee joint alter neural signaling from the injured area that restricts activation of surrounding muscle $[3,4]$. This protective response, combined with periods of limb immobilization and declines in habitual physical activity, induces rapid muscle disuse atrophy due to unloading and reduced neural activation of muscle [5,6]. Developing interventions that mitigate disuse atrophy following ACL injury and subsequent reconstruction may accelerate and optimize recovery. 
Disuse atrophy is driven by a persistent negative net muscle protein balance (muscle protein synthesis [MPS] < muscle protein breakdown [MPB]) that results, in part, from decreased postprandial MPS [7]. This "anabolic resistance" to protein ingestion is robust [8,9], and contributes to a rapid suppression of integrated MPS (i.e., measure incorporating fed and fasted states) during periods of disuse [10]. Dietary protein quality (i.e., essential amino acid [EAA] content, digestion and absorption kinetics) and quantity modulate postprandial MPS [11], suggesting protein-based interventions may be used to restore integrated MPS under disuse conditions. Increasing leucine content of the diet enhances integrated MPS in older populations that experience anabolic resistance due to aging [12-14]. Manipulating protein intake also modulates MPS in some [15] but not all experimental models of disuse (i.e., limb immobilization and bed rest) [16-18]. No study to our knowledge has examined the capacity of protein-based interventions to chronically stimulate MPS during periods of disuse associated with musculoskeletal injury.

Increasing protein intake during periods of disuse before ACL reconstruction may restore anabolism and attenuate muscle loss to better prepare a patient for the metabolic demand for protein during surgery and early postoperative recovery (i.e., maintain 'reserve' of amino acids) $[19,20]$. Protein-based interventions before surgery may also enhance muscle regenerative capacity, as pre-operative EAA supplementation increased satellite cell abundance in total knee arthroplasty patients [21]. The objective of this study was to determine the effect of a high-quality, optimal protein diet (OP; $2.0 \mathrm{~g} \cdot \mathrm{kg}^{-1} \cdot \mathrm{d}^{-1}$ ) compared to adequate protein diet (AP; $1.0 \mathrm{~g} \cdot \mathrm{kg}^{-1} \cdot \mathrm{d}^{-1}$ ) for two weeks before ACL reconstruction on integrated myofibrillar protein synthesis (MyoPS) and proteolytic gene expression. Myogenic regulatory factor gene expression on the day of surgery was a secondary outcome. We hypothesized that OP compared to AP diets would enhance integrated MyoPS during the two-week intervention period, and decrease proteolytic gene expression and enhance myogenic regulatory factor gene expression at the time of surgery.

\section{Materials and Methods}

\subsection{Participants}

Six men aged 19-39 scheduled to undergo their first ACL reconstruction were recruited to participate. Two participating surgeons identified eligible patients that were subsequently screened by study personnel for all eligibility requirements. Exclusion criteria included body mass indexes (BMI) greater than 30, metabolic or cardiovascular abnormalities, food allergies, and gastrointestinal disorders (e.g., lactose intolerance). Individuals that reported using nutritional or herbal supplements, anabolic steroids, and tobacco products were excluded from participation. The study purpose, the experimental protocol, and potential risks were explained to participants before they gave written informed consent to participate. This study was approved by the Institutional Review Boards at Hartford Hospital (Hartford, CT, USA) and the University of Connecticut (Storrs, CT, USA), and was registered with ClinicalTrials.gov as NCT03492021.

\subsection{Experimental Design}

This study was a two-arm parallel-trial design with subjects randomly assigned (1:1 randomization) to AP or OP groups prescribed 1.0 or $2.0 \mathrm{~g}$ protein $\cdot \mathrm{kg}^{-1} \cdot \mathrm{d}^{-1}$, respectively, for two weeks before surgery. Daily deuterium oxide $\left(\mathrm{D}_{2} \mathrm{O}\right)$ ingestion followed by vastus lateralis muscle biopsies and blood draws during surgery were used to measure integrated MyoPS rates. Muscle biopsies collected during surgery were also used to assess skeletal muscle myogenic and proteolytic gene expression.

\subsection{Dietary Intake}

Participants consumed a eucaloric diet prescribing approximately 1.0 or $2.0 \mathrm{~g}$ protein $\cdot \mathrm{kg}^{-1} \cdot \mathrm{d}^{-1}$ (AP or OP), 30\% of energy intake from fat, and the remaining calories from carbohydrates beginning two weeks before surgery. Individual energy requirements were established relative to estimated resting energy expenditure (Harris-Benedict equa- 
tion), level of physical activity, and estimated energy intake reported at baseline. Food intake was assessed at baseline to characterize typical consumption of each macronutrient (i.e., amount and sources). One-week cycle menus were individualized for each participant based on their energy requirements and routine food consumption. Five servings ( $3 \mathrm{oz}$ each) of beef were provided to participants in the OP group each week as a high-quality protein source. OP and AP participants consumed one serving of a beef-based protein supplement (IsoPrime Beef $^{\mathrm{TM}}$ ) or an isocaloric serving of Powerade ${ }^{\circledR}$ twice a week, respectively. Menus were designed to distribute dietary protein evenly throughout the day (breakfast, lunch, dinner), with OP consuming additional protein as between-meal snacks. A study dietician remained in close contact with participants as they began their individualized study diets and throughout the intervention period. A 7-day food record was collected before surgery to evaluate dietary intake. Participants were provided detailed instructions for filling out the food record, and any discrepancies between prescribed diets and reported intake were reviewed with participants. Food records were analyzed using Nutritionist Pro ${ }^{\mathrm{TM}}$ software (Axxya Systems, Woodinville, WA, USA) to estimate total energy, protein, and amino acid content of the diet.

\subsection{Deuterium Oxide Labeling}

$\mathrm{D}_{2} \mathrm{O}$ labeling of the newly synthesized myofibrillar protein fraction was achieved using daily oral consumption of $70 \% \mathrm{D}_{2} \mathrm{O}$. Participants ingested three $50 \mathrm{~mL}$ aliquots of $70 \%$ $\mathrm{D}_{2} \mathrm{O}$ (150 mL/day) on days $0-7$, and two $50 \mathrm{~mL}$ aliquots $(100 \mathrm{~mL} /$ day) on days 8-14 before surgery. All $50 \mathrm{~mL}$ aliquots were separated by at least $3 \mathrm{~h}$. This method of $\mathrm{D}_{2} \mathrm{O}$ ingestion rapidly increases and maintains body water enrichment at $1-2 \%[16,22,23]$. Participants recorded the date and time of each $\mathrm{D}_{2} \mathrm{O}$ dose and returned empty bottles to study staff to monitor compliance.

\subsection{Tissue Sampling during ACL Reconstruction}

Participants were admitted on the morning of their ACL reconstruction in a fasted state. Participants were initially anesthetized with intravenous propofol and maintained with inhalation anesthetic (sevoflurate) during surgery. Regional anesthesia consisting of an adductor canal and geniculate nerve block (0.25\% Marcaine with 1:200,000 epinephrine) was also administered. A pneumatic tourniquet was applied as high as possible on the thigh of the injured limb during sterile preparation and draping. A blood sample was obtained and the tourniquet was subsequently inflated to a pressure of $250 \mathrm{mmHG}$. Vastus lateralis muscle biopsies were collected within 5 min of tourniquet inflation using Rongeur forceps through the incision made for the ACL reconstruction. Muscle tissue was carefully dissected to remove all visible fat and connective tissue, and was snap frozen in liquid nitrogen. All samples were stored at $-80{ }^{\circ} \mathrm{C}$ until analysis.

\subsection{Myofibrillar Protein Synthesis}

Muscle samples collected during ACL reconstruction were used to measure integrated MyoPS ( $\mathrm{D}_{2} \mathrm{O}$ labeling of alanine in myofibrillar protein fraction) during the two weeks before surgery. The myofibrillar protein fraction was isolated from $~ 50 \mathrm{mg}$ of muscle using methods described previously by Damas et al. [24]. In brief, amino acids from isolated myofibrillar proteins were released by adding $1 \mathrm{~mL} \mathrm{HCl}(1 \mathrm{~m})$ and $1 \mathrm{~mL}$ of Dowex resin (50WX8-200 resin; Sigma-Aldrich, Saint Louis, MI, USA) with $\mathrm{HCl}$ (0.5 m). Samples were heated at $100^{\circ} \mathrm{C}$ for $72 \mathrm{~h}$ with vortex mixing every $24 \mathrm{~h}$, and subsequently eluted from the resin $\left(2 \mathrm{M} \mathrm{NH}_{4} \mathrm{OH}\right)$ and evaporated to dryness. Metabolic Solutions Inc. (Nashua, $\mathrm{NH}$, USA) analyzed the muscle preparations for the incorporation of deuterated alanine with a gas chromatograph (GC)—pyrolysis—isotope ratio mass spectrometer (IRMS) (Thermo Finnigan (San Jose, CA, USA) Delta V isotope IRMS coupled to a Thermo Trace GC Ultra with a GC pyrolysis interface III) using previously described methods [24].

Plasma samples were analyzed for $\mathrm{D}_{2} \mathrm{O}$ enrichment by cavity ring-down spectroscopy using a Liquid Water Isotope Analyzer with automated injection system (version 2 upgrade, 
Los Gatos Research, Mountain View, CA, USA) [25]. Plasma proteins were removed by adding approximately $5 \mathrm{mg}$ zinc sulfate monohydrate to $25-50 \mu \mathrm{L}$ plasma in a microcentrifuge tube. Samples were vortexed and spun at $8000 \mathrm{rpm}$ to precipitate proteins. The plasma protein-free supernatant was injected eight times and the average of the last three measurements was used for analysis. Standard curves were generated before and after samples to calculate $\mathrm{D}_{2} \mathrm{O}$ enrichment as $\delta^{2} \mathrm{H}$ per mil (\%) relative to Vienna Standard Mean Ocean Water (VSMOW). Intra-run precision was less than $2 \delta \%$ and inter-run precision was less than $3.5 \delta \%$. The $\delta^{2} \mathrm{H}$ values were converted to atom percent (Atm\%) as previously described [26]:

$$
\operatorname{Atm} \%=\frac{100 \times A R \times\left(\delta^{2} \mathrm{H} \times 0.001+1\right)}{1+A R \times\left(\delta^{2} \mathrm{H} \times 0.001+1\right)}
$$

where AR is the absolute ratio constant for $\mathrm{D}_{2} \mathrm{O}(0.0015576)$ and $\delta^{2} \mathrm{H}$ is the value in \%o to be converted into Atm\%.

The myofibrillar protein fractional synthesis rate $\left(\mathrm{FSR}, \% \cdot\right.$ day $^{-1}$ ) was determined by measuring the incorporation of $\mathrm{D}_{2} \mathrm{O}$-labeled alanine into myofibrillar protein. Plasmaderived body water enrichment (multiplied by 3.7 to account for the exchange of $\mathrm{D}_{2} \mathrm{O}$ between body water and alanine, and divided by 11 to correct for the total number of hydrogens in the derivative) was used as the precursor. FSR was calculated using the standard precursor-product equation:

$$
\operatorname{FSR}\left(\% \cdot \mathrm{d}^{-1}\right)=\left[\left(\mathrm{APE}_{\mathrm{Ala}}\right)\right] /\left[\left(\mathrm{APE}_{\mathrm{p}}\right) \times \mathrm{t}\right] \times 100
$$

where atm\% excess $(\mathrm{APE})_{\mathrm{Ala}}$ is the $\mathrm{D}_{2} \mathrm{O}$ enrichment of protein-bound alanine, $\mathrm{APE}_{\mathrm{p}}$ is the mean $\mathrm{D}_{2} \mathrm{O}$ enrichment of total body water (in atm\% excess), and $t$ is the duration of $\mathrm{D}_{2} \mathrm{O}$ labeling in days. $\mathrm{APE}_{\mathrm{Ala}}$ and $\mathrm{APE}_{\mathrm{p}}$ were calculated as day of surgery values minus estimates of baseline myofibrillar protein and plasma $\mathrm{D}_{2} \mathrm{O}$ enrichment $(0.0135$ and $0.0154 \%$, respectively). Estimates of baseline enrichment were derived from levels previously measured by Metabolic Solutions Inc in a population of young men [24].

\section{7. mRNA Expression}

TRIzol reagent (ThermoFisher, Waltham, MA, USA) was used to isolate total RNA from $\sim 20 \mathrm{mg}$ of muscle to determine expression of several genes linked to skeletal muscle myogenesis and proteolysis. Quantity and quality of isolated RNA were assessed using a NanoDrop ND-2000 spectrophotometer (NanoDrop, Wilmington, DE, USA). Equal amounts of total RNA $(500 \mu \mathrm{g})$ were reverse-transcribed into cDNA (High-Capacity cDNA RT Kit, Applied Biosystems, Foster City, CA, USA) using a T100 ${ }^{\mathrm{TM}}$ Thermal Cycler (BioRad, Hercules, CA, USA). mRNA expression of paired box 7 (Pax7), MyoD, Myogenin, myogenic factor 5 (Myf5), myogenic factor 6 (Myf6), muscle atrophy F-box (MAFbx), and muscle RING finger-1 (MuRF1) were determined using commercially available TaqMan ${ }^{\circledR}$ probes (Applied Biosystems). Samples were run in $10 \mu \mathrm{L}$ reactions in duplicate using TaqMan fast advanced master mix with a Step One Plus Real-Time PCR system (Applied Biosystems). Data were normalized to the geometric mean of $\beta$-actin and $\beta 2$ microglobulin, and expressed for all participants as a fold change relative to AP values using the $\Delta \Delta C_{T}$ method [27]. Sample size for Myf5 was five participants (average CT threshold of $32.8 \pm 1.4$ ) since data were not generated for one person in the AP group whose sample failed to cross the CT threshold prior to 40 cycles.

\subsection{Statistical Analysis}

Differences between AP and OP for baseline characteristics, dietary intake, integrated MyoPS, and myogenic and proteolytic gene expression were analyzed using unpaired $t$ tests. The association between MyoPS and gene expression was examined using Pearson's correlation coefficient. Gene data for correlations were $\log _{2}$ transformed, since negative fold change means are on a scale of $0-1$ while positive data are $>1$, resulting in uneven 
scales. Normality was assessed using Shapiro-Wilk tests for dependent variables. Given the small number of participants, effect size was determined as biased corrected Hedge's $g$ with thresholds of 0.2 (small), 0.5 (moderate), and 0.8 (large). All data are presented as the means \pm SD. The $\alpha$ level of significance for all statistical tests was two-tailed and set at $p<0.05$. We also reported values with $p<0.1$ as trending toward significance. Data were analyzed using IBM SPSS Statistics for Windows version 26 (IBM, Armonk, NY, USA).

\section{Results}

\subsection{Participants}

The 6 male participants were $30 \pm 9$ years old and had an average BMI of $25.1 \pm 2.1$ which did not differ between groups ( $p>0.05$; Table 1$)$.

Table 1. Participant Characteristics ${ }^{1}$.

\begin{tabular}{cccc}
\hline & AP & OP & $p$ Value \\
\hline Age $(\mathrm{y})$ & $32 \pm 11$ & $30 \pm 7$ & 0.78 \\
Height $(\mathrm{m})$ & $1.8 \pm 0.1$ & $1.8 \pm 0.1$ & 0.75 \\
Weight $(\mathrm{kg})$ & $85.3 \pm 8.2$ & $76.2 \pm 14.5$ & 0.45 \\
Body mass index & $26.2 \pm 1.6$ & $23.9 \pm 2.2$ & 0.25 \\
\hline
\end{tabular}

${ }^{1}$ Values are the mean \pm SD. Differences between AP $(n=3)$ and OP $(n=3)$ were examined using unpaired $t$ tests and were not different between groups. AP, adequate protein; $\mathrm{OP}$, optimal protein.

\subsection{Dietary Intake}

Average protein intake derived from dietary records was greater in OP compared to $\operatorname{AP}\left(1.9 \pm 0.2 \mathrm{~g} \cdot \mathrm{kg}^{-1} \cdot \mathrm{d}^{-1}\right.$ and $1.2 \mathrm{~g} \cdot \mathrm{kg}^{-1} \cdot \mathrm{d}^{-1} ; p<0.05$; Table 2$)$. Total branched chain amino acids, leucine, and valine were also greater in OP compared to AP $(p<0.05)$.

Table 2. Preoperative Dietary Intake ${ }^{1}$.

\begin{tabular}{|c|c|c|c|}
\hline & AP & OP & $p$ Value \\
\hline Energy $(\mathrm{kcal} / \mathrm{d})$ & $2367 \pm 125$ & $2853 \pm 382$ & 0.10 \\
\hline Carbohydrate $\left(\mathrm{g} \cdot \mathrm{kg}^{-1} \cdot \mathrm{d}^{-1}\right)$ & $3.7 \pm 0.6$ & $4.3 \pm 1.8$ & 0.60 \\
\hline Fat $\left(\mathrm{g} \cdot \mathrm{kg}^{-1} \cdot \mathrm{d}^{-1}\right)$ & $1.0 \pm 0.1$ & $1.4 \pm 0.3$ & 0.06 \\
\hline Protein $\left(\mathrm{g} \cdot \mathrm{kg}^{-1} \cdot \mathrm{d}^{-1}\right)$ & $1.2 \pm 0.0$ & $1.9 \pm 0.2$ & 0.01 \\
\hline Leucine $\left(\mathrm{mg} \cdot \mathrm{kg}^{-1} \cdot \mathrm{d}^{-1}\right)$ & $73 \pm 10$ & $104 \pm 14$ & 0.04 \\
\hline Isoleucine $\left(\mathrm{mg} \cdot \mathrm{kg}^{-1} \cdot \mathrm{d}^{-1}\right)$ & $42 \pm 7$ & $58 \pm 8$ & 0.06 \\
\hline Valine $\left(\mathrm{mg} \cdot \mathrm{kg}^{-1} \cdot \mathrm{d}^{-1}\right)$ & $48 \pm 7$ & $68 \pm 9$ & 0.04 \\
\hline Total BCAAs $\left(\mathrm{mg} \cdot \mathrm{kg}^{-1} \cdot \mathrm{d}^{-1}\right)$ & $162 \pm 24$ & $230 \pm 32$ & 0.04 \\
\hline
\end{tabular}

${ }^{1}$ Values are the mean \pm SD. Differences between AP $(n=3)$ and OP $(n=3)$ were examined using unpaired $t$ tests $\mathrm{AP}$, adequate protein; $\mathrm{BCAA}$, branched chain amino acids; OP, optimal protein.

\subsection{Myofibrillar Protein Synthesis}

$\mathrm{D}_{2} \mathrm{O}$ enrichment of total body water was not different in OP compared to AP participants on the day of surgery $(1.3 \pm 0.4 \%$ and $1.3 \pm 0.4 \% ; p=0.90)$. MyoPS over the two-week intervention period tended to be greater in OP compared to AP participants $(p=0.076$; Figure 1). There was a large effect size $(g=1.56)$ for between-group differences in MyoPS.

\section{4. mRNA Expression}

Myogenic (MyoD, myogenin, Pax7, Myf5, and Myf6) and proteolytic (MAFbx, MuRF1) gene expression was not different between groups (Table 3; $p>0.05$ ). There was a large effect size (1.05) for between-group differences in MuRF1 gene expression. MuRF1 gene expression was negatively associated with MyoPS ( $\mathrm{r}=-0.817, p=0.047$; Figure 2), and MyoPS was not associated with any other markers of myogenesis or proteolysis $(p>0.05$; data not shown). 


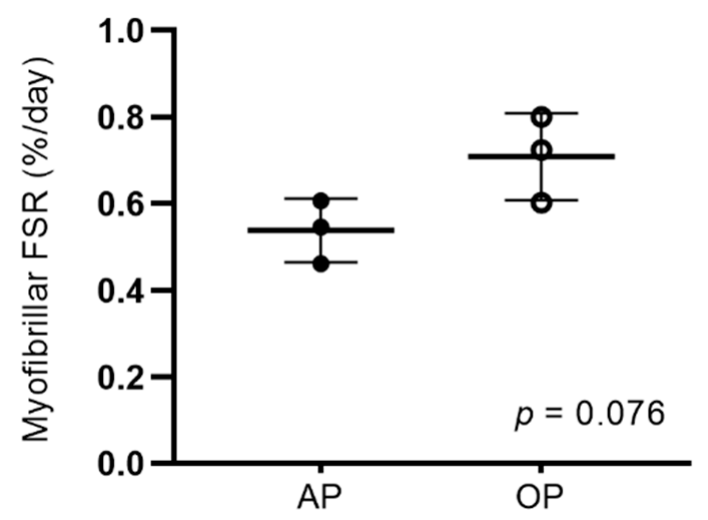

Figure 1. Myofibrillar FSR $\left(\% \cdot \mathrm{d}^{-1}\right)$ over a two week period before ACL reconstruction with AP $\left(1.2 \mathrm{~g} \cdot \mathrm{kg}^{-1} \cdot \mathrm{d}^{-1}\right)$ and OP $\left(1.9 \mathrm{~g} \cdot \mathrm{kg}^{-1} \cdot \mathrm{d}^{-1}\right)$. Differences between AP $(n=3)$ and OP $(n=3)$ were examined using unpaired $t$ tests. Values are the mean \pm SD. AP, adequate protein; FSR, fractional synthesis rate; OP, optimal protein.

Table 3. Myogenic and proteolytic gene expression ${ }^{1}$.

\begin{tabular}{ccccc}
\hline & AP & OP & $p$ Value & Effect Size \\
\hline Myogenesis & & & & \\
MyoD & $1.00 \pm 0.11$ & $1.53 \pm 0.94$ & 0.39 & 0.63 \\
Myogenin & $1.03 \pm 0.31$ & $1.12 \pm 0.23$ & 0.72 & 0.25 \\
Pax7 & $1.20 \pm 0.92$ & $0.79 \pm 0.16$ & 0.48 & 0.51 \\
Myf5 & $1.17 \pm 0.85$ & $0.89 \pm 0.14$ & 0.60 & 0.35 \\
Myf6 & $1.10 \pm 0.52$ & $0.96 \pm 0.43$ & 0.74 & 0.24 \\
Proteolysis & & & & 0.31 \\
MAFbx & $1.10 \pm 0.50$ & $0.94 \pm 0.24$ & 0.66 & 1.05 \\
MuRF1 & $1.04 \pm 0.34$ & $0.66 \pm 0.23$ & 0.18 & \\
\hline
\end{tabular}

${ }^{1}$ Values are the mean \pm SD. Differences between AP ( $n=3 ; n=2$ for Myf5) and OP ( $\left.n=3\right)$ were examined using unpaired $t$ tests. AP, adequate protein; MAFbx, muscle atrophy F-box; MuRF1, muscle RING finger-1; Myf5, myogenic factor 5; Myf6, myogenic factor 6; OP, optimal protein; Pax7, paired box 7.

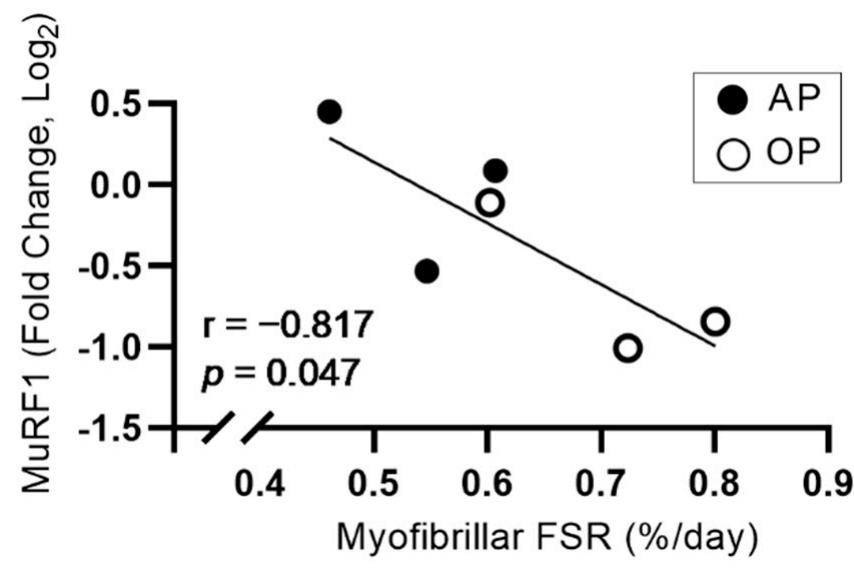

Figure 2. Relationship between myofibrillar FSR $\left(\% \cdot \mathrm{d}^{-1}\right)$ and MuRF1 gene expression in AP and OP. Associations were examined using Pearson's correlation. AP, adequate protein; FSR, fractional synthesis rate; OP, optimal protein.

\section{Discussion}

This pilot study showed that patients consuming a high-quality, OP diet (1.9 g protein $\cdot \mathrm{kg}^{-1} \cdot \mathrm{d}^{-1}$ ) for two weeks before ACL reconstruction tended to have greater MyoPS over the intervention period compared to those consuming an AP diet $\left(1.2 \mathrm{~g}\right.$ protein $\left.\cdot \mathrm{kg}^{-1} \cdot \mathrm{d}^{-1}\right)$. While myogenic and proteolytic gene expression were the same in both groups on the day of surgery, MuRF1 expression was inversely associated with MyoPS. These findings suggest 
a potential stimulatory effect of increased protein intake on MyoPS during injury-mediated disuse conditions.

The large effect size and tendency for increased MyoPS in OP compared to AP is consistent with the stimulatory effect of protein and free amino acids reported in healthy individuals under normal conditions. Oikawa et al. [28] showed that consuming a potato protein supplement twice daily to elevate protein intake from 0.8 to $1.6 \mathrm{~g}$ protein $\cdot \mathrm{kg}^{-1} \cdot \mathrm{d}^{-1}$ in healthy young women increased integrated MyoPS by $0.14 \pm 0.09 \% \cdot \mathrm{d}^{-1}$. A comparable difference in protein intake between AP and OP in the current study $\left(0.7 \mathrm{~g} \cdot \mathrm{kg}^{-1} \cdot \mathrm{d}^{-1}\right)$ resulted in a similar magnitude of difference in MyoPS (mean difference \pm pooled SD; $0.17 \pm 0.09 \% \cdot \mathrm{d}^{-1}$ ). Contrary to our findings, Kilroe et al. [17] showed that graded protein intakes of $0.15,0.5$, and $1.6 \mathrm{~g} \cdot \mathrm{kg}^{-1} \cdot \mathrm{d}^{-1}$ had no effect on MyoPS during three days of experimental disuse (i.e., unilateral leg immobilization). This discrepancy is likely due to differences in diet duration (three days vs. two weeks) or general differences between experimental and injury-mediated disuse conditions (i.e., intramuscular inflammation [29]). Mitchell et al. [16] showed that consuming $20 \mathrm{~g}$ of supplemental dairy protein daily during 14 days of immobilization had no effect on MyoPS compared to a placebo. The supplemental protein did attenuate disuse-induced declines in intracellular signaling regulating MyoPS (i.e., mechanistic target of rapamycin [mTOR]-mediated anabolic signaling) [30], suggesting a potential protective effect of increased protein intake during disuse similar to the current study. While some disparities exist, results from previous work collectively support our findings suggesting increased protein intake before ACL reconstruction may have a protective stimulatory effect on MyoPS.

Satellite cell abundance is reduced following ACL injury, which may impair muscle regenerative capacity [31]. Muyskens et al. [21] showed that increasing protein intake by consuming $20 \mathrm{~g}$ of EAA twice daily for 7 days before total knee arthroplasty increased muscle satellite cell abundance compared to a placebo. In the current study, markers of myogenesis were not different and had only small or moderate effect sizes between AP and OP groups. This discrepancy may be due to differences in outcomes measured, as we reported gene expression regulating satellite cell activity, while Muyskens et al. used histology and immunofluorescence to report the number of satellite cells in images of muscle tissue sections. Future work should consider examining both outcomes to comprehensively characterize the effect of protein-based interventions on satellite cell abundance and upstream regulation. Transcript levels of the proteolytic markers MAFbx and MuRF1 were also similar in AP and OP in the current study. However, there was a large effect size for decreased MuRF1 gene expression in OP compared to AP $(g=1.01)$, and an inverse association between MyoPS and MuRF1 expression $(r=-0.817)$. These findings support the idea that a high-protein diet stimulating MyoPS before surgery may promote a more favorable anabolic environment than a lower protein diet by attenuating MPB. Since these findings did not extend to MAFbx, and changes in proteolytic gene expression do not always translate to changes in protein content [32] or measured rates of MPB [33], a more comprehensive analysis examining the influence of dietary protein on MPB during periods of disuse before ACL reconstruction is needed.

While this pilot study indicates a potential benefit of consuming OP compared to AP before ACL reconstruction, some limitations must be acknowledged when interpreting these findings and their potential implications. Since this is a pilot study, this work was underpowered to observe statistical differences between groups. Sample size calculations for MyoPS ( $\alpha=0.05, \beta=0.20$ ) using a mean between-group difference of $0.17 \% \cdot$ day $^{-1}$ and a common standard deviation of $0.09 \% \cdot$ day $^{-1}$ indicate a sample size of five participants per group may be required to observe a statistical difference. Another potential limitation is the use of historical baseline enrichment values for calculating APE, as temporal drifts in values generated from the same GC-pyrolysis-IRMS may result in underestimation of FSR. This may have contributed to lower FSR in the current work than previously reported [17]. 


\section{Conclusions}

This pilot study showed that MyoPS tended to be greater in patients consuming a high-quality, OP diet $\left(1.9 \mathrm{~g}\right.$ protein $\left.\cdot \mathrm{kg}^{-1} \cdot \mathrm{d}^{-1}\right)$ versus an AP diet $\left(1.2 \mathrm{~g}\right.$ protein $\left.\cdot \mathrm{kg}^{-1} \cdot \mathrm{d}^{-1}\right)$ for two weeks before ACL reconstruction. While markers of protein breakdown and muscle regeneration were not different between groups at the time of surgery, patients with greater MyoPS exhibited lower levels of proteolytic gene expression. These data may indicate some benefit of increasing protein intake during periods of disuse before ACL reconstruction; however, the sample size in this pilot study was too small to observe statistical differences. Stimulating MyoPS during periods of injury-mediated disuse may protect muscle mass and optimize recovery. Whether these pilot data translate to a preservation of muscle mass and improved recovery is unknown and should be addressed in future work.

Author Contributions: N.R.R., C.J.L. and E.E.H. designed the research; E.E.H., N.R.R., M.A.F., C.J.L., C.G.R. and E.M.M. performed the research; E.E.H., N.R.R., L.M.M. and S.M.P. analyzed the data; E.E.H., N.R.R., L.M.M. and S.M.P. interpreted the results; E.E.H. prepared the tables and figures; E.E.H. drafted the manuscript. All authors have read and agreed to the published version of the manuscript.

Funding: This work was supported in part by The Beef Checkoff, KFS63669550 (N.R.R.); the USDA National Institute of Food and Agriculture, Hatch project, accession \#1016873 (N.R.R.); and by a fellowship appointment at the U.S. Army Research Institute of Environmental Medicine (to E.E.H.) administered by the Oak Ridge Institute for Science and Education through an interagency agreement between the U.S. Department of Energy and the US Army Medical Research and Development Command.

Institutional Review Board Statement: This study was conducted according to the guidelines of the Declaration of Helsinki, and approved by the Institutional Review Board of Hartford Hospital (E-HHC-2016-0126) and the University of Connecticut (HHC-E-HHC-2016-0126).

Informed Consent Statement: Informed consent was obtained from all subjects involved in this study.

Data Availability Statement: Data are available upon request from corresponding author.

Acknowledgments: The authors wish to thank the Clinical Director of the Glastonbury Surgery Center and other participating support staff for their significant contributions to study management and data collection.

Conflicts of Interest: N.R.R. serves on speaker bureaus for the National Cattlemen's Beef Association and National Dairy Council, and serves on Danone's Sports Nutrition Advisory Board. Funding sources were not involved in this study and did not have any restrictions regarding publication. The opinions or assertions contained herein are the private views of the authors and are not to be construed as official or as reflecting the views of the Army or the Department of Defense. Any citations of commercial organizations and trade names in this report do not constitute an official Department of the Army endorsement of approval of the products or services of these organizations.

\section{References}

1. Norte, G.E.; Knaus, K.R.; Kuenze, C.; Handsfield, G.G.; Meyer, C.H.; Blemker, S.S.; Hart, J.M. MRI-Based Assessment of LowerExtremity Muscle Volumes in Patients Before and After ACL Reconstruction. J. Sport Rehabil. 2018, 27, 201-212. [CrossRef] [PubMed]

2. Thomas, A.C.; Wojtys, E.M.; Brandon, C.; Palmieri-Smith, R.M. Muscle atrophy contributes to quadriceps weakness after anterior cruciate ligament reconstruction. J. Sci. Med. Sport 2015, 19, 7-11. [CrossRef] [PubMed]

3. Rice, D.A.; McNair, P.J. Quadriceps Arthrogenic Muscle Inhibition: Neural Mechanisms and Treatment Perspectives. Semin. Arthritis Rheum. 2010, 40, 250-266. [CrossRef] [PubMed]

4. Spencer, J.D.; Hayes, K.C.; Alexander, I.J. Knee joint effusion and quadriceps reflex inhibition in man. Arch. Phys. Med. Rehabil. 1984, 65, 171-177.

5. Kilroe, S.P.; Fulford, J.; Jackman, S.R.; VAN Loon, L.J.C.; Wall, B.T. Temporal Muscle-specific Disuse Atrophy during One Week of Leg Immobilization. Med. Sci. Sports Exerc. 2019, 52, 944-954. [CrossRef]

6. Wall, B.T.; Dirks, M.; Snijders, T.; Senden, J.M.G.; Dolmans, J.; Van Loon, L.J.C. Substantial skeletal muscle loss occurs during only 5 days of disuse. Acta Physiol. 2013, 210, 600-611. [CrossRef]

7. Phillips, S.M.; Glover, E.I.; Rennie, M.J. Alterations of protein turnover underlying disuse atrophy in human skeletal muscle. J. Appl. Physiol. 2009, 107, 645-654. [CrossRef] 
8. Wall, B.T.; Snijders, T.; Senden, J.M.G.; Ottenbros, C.L.P.; Gijsen, A.P.; Verdijk, L.; van Loon, L.J. Disuse Impairs the Muscle Protein Synthetic Response to Protein Ingestion in Healthy Men. J. Clin. Endocrinol. Metab. 2013, 98, 4872-4881. [CrossRef]

9. Wall, B.T.; Dirks, M.; Snijders, T.; van Dijk, J.-W.; Fritisch, M.; Verdijk, L.; Van Loon, L.J.C. Short-term muscle disuse lowers myofibrillar protein synthesis rates and induces anabolic resistance to protein ingestion. Am. J. Physiol. Metab. 2016, 310, E137-E147. [CrossRef]

10. Kilroe, S.P.; Fulford, J.; Holwerda, A.; Jackman, S.R.; Lee, B.P.; Gijsen, A.P.; van Loon, L.J.; Wall, B.T. Short-term muscle disuse induces a rapid and sustained decline in daily myofibrillar protein synthesis rates. Am. J. Physiol. Metab. 2020, 318, E117-E130. [CrossRef]

11. Gwin, J.A.; Church, D.D.; Wolfe, R.R.; Ferrando, A.A.; Pasiakos, S.M. Muscle Protein Synthesis and Whole-Body Protein Turnover Responses to Ingesting Essential Amino Acids, Intact Protein, and Protein-Containing Mixed Meals with Considerations for Energy Deficit. Nutrients 2020, 12, 2457. [CrossRef] [PubMed]

12. Devries, M.C.; McGlory, C.; Bolster, D.R.; Kamil, A.; Rahn, M.; Harkness, L.; Baker, S.K.; Phillips, S. Protein leucine content is a determinant of shorter- and longer-term muscle protein synthetic responses at rest and following resistance exercise in healthy older women: A randomized, controlled trial. Am. J. Clin. Nutr. 2018, 107, 217-226. [CrossRef] [PubMed]

13. Casperson, S.; Sheffield-Moore, M.; Hewlings, S.J.; Paddon-Jones, D. Leucine supplementation chronically improves muscle protein synthesis in older adults consuming the RDA for protein. Clin. Nutr. 2012, 31, 512-519. [CrossRef]

14. Murphy, C.H.; I Saddler, N.; Devries, M.C.; McGlory, C.; Baker, S.K.; Phillips, S.M. Leucine supplementation enhances integrative myofibrillar protein synthesis in free-living older men consuming lower- and higher-protein diets: A parallel-group crossover study. Am. J. Clin. Nutr. 2016, 104, 1594-1606. [CrossRef] [PubMed]

15. Paddon-Jones, D.; Sheffield-Moore, M.; Urban, R.J.; Sanford, A.P.; Aarsland, A.; Wolfe, R.R.; Ferrando, A.A. Essential Amino Acid and Carbohydrate Supplementation Ameliorates Muscle Protein Loss in Humans during 28 Days Bedrest. J. Clin. Endocrinol. Metab. 2004, 89, 4351-4358. [CrossRef] [PubMed]

16. Mitchell, C.; D’Souza, R.F.; Mitchell, S.M.; Figueiredo, V.C.; Miller, B.F.; Hamilton, K.L.; Peelor, F.F.; Coronet, M.; Pileggi, C.A.; Durainayagam, B.; et al. Impact of dairy protein during limb immobilization and recovery on muscle size and protein synthesis; a randomized controlled trial. J. Appl. Physiol. 2018, 124, 717-728. [CrossRef] [PubMed]

17. Kilroe, S.P.; Fulford, J.; Jackman, S.; Holwerda, A.; Gijsen, A.; van Loon, L.; Wall, B.T. Dietary protein intake does not modulate daily myofibrillar protein synthesis rates or loss of muscle mass and function during short-term immobilization in young men: A randomized controlled trial. Am. J. Clin. Nutr. 2020, 113, 548-561. [CrossRef] [PubMed]

18. Edwards, S.J.; Smeuninx, B.; McKendry, J.; Nishimura, Y.; Luo, D.; Marshall, R.N.; Perkins, M.; Ramsay, J.; Joanisse, S.; Philp, A.; et al. High-dose leucine supplementation does not prevent muscle atrophy or strength loss over 7 days of immobilization in healthy young males. Am. J. Clin. Nutr. 2020, 112, 1368-1381. [CrossRef]

19. Gillis, C.; Ljungqvist, O.; Carli, F. Prehabilitation, enhanced recovery after surgery, or both? A narrative review. Br. J. Anaesth. 2022. [CrossRef]

20. Gillis, C.; Wischmeyer, P.E. Pre-operative nutrition and the elective surgical patient: Why, how and what? Anaesthesia 2019, 74, 27-35. [CrossRef]

21. Muyskens, J.B.; Foote, D.M.; Bigot, N.J.; Strycker, L.A.; Smolkowski, K.; Kirkpatrick, T.K.; Lantz, B.A.; Shah, S.N.; Mohler, C.G.; Jewett, B.A.; et al. Cellular and morphological changes with EAA supplementation before and after total knee arthroplasty. J. Appl. Physiol. 2019, 127, 531-545. [CrossRef] [PubMed]

22. Robinson, M.M.; Turner, S.M.; Hellerstein, M.K.; Hamilton, K.L.; Miller, B.F. Long-term synthesis rates of skeletal muscle DNA and protein are higher during aerobic training in older humans than in sedentary young subjects but are not altered by protein supplementation. FASEB J. 2011, 25, 3240-3249. [CrossRef]

23. Loomba, R.; Decaris, M.; Li, K.W.; Shankaran, M.; Mohammed, H.; Matthews, M.; Richards, L.M.; Nguyen, P.; Rizo, E.; Andrews, B.; et al. Discovery of Half-life of Circulating Hepatitis B Surface Antigen in Patients with Chronic Hepatitis B Infection Using Heavy Water Labeling. Clin. Infect. Dis. 2018, 69, 542-545. [CrossRef] [PubMed]

24. Damas, F.; Phillips, S.M.; Libardi, C.A.; Vechin, F.C.; Lixandrão, M.E.; Jannig, P.R.; Costa, L.A.R.; Bacurau, A.V.; Snijders, T.; Parise, G.; et al. Resistance training-induced changes in integrated myofibrillar protein synthesis are related to hypertrophy only after attenuation of muscle damage. J. Physiol. 2016, 594, 5209-5222. [CrossRef] [PubMed]

25. Berman, E.S.F.; Fortson, S.L.; Snaith, S.P.; Gupta, M.; Baer, D.S.; Chery, I.; Blanc, S.; Melanson, E.L.; Thomson, P.J.; Speakman, J.R Direct Analysis of $\delta 2 \mathrm{H}$ and $\delta 18 \mathrm{O}$ in Natural and Enriched Human Urine Using Laser-Based, Off-Axis Integrated Cavity Output Spectroscopy. Anal. Chem. 2012, 84, 9768-9773. [CrossRef] [PubMed]

26. Wilkinson, D.J.; Franchi, M.V.; Brook, M.; Narici, M.V.; Williams, J.P.; Mitchell, W.K.; Szewczyk, N.J.; Greenhaff, P.; Atherton, P.J.; Smith, K. A validation of the application of $\mathrm{D}_{2} \mathrm{O}$ stable isotope tracer techniques for monitoring day-to-day changes in muscle protein subfraction synthesis in humans. Am. J. Physiol. Metab. 2014, 306, E571-E579. [CrossRef]

27. Pfaffl, M.W. A new mathematical model for relative quantification in real-time RT-PCR. Nucleic Acids Res. 2001, 29, e45. [CrossRef]

28. Oikawa, S.Y.; Bahniwal, R.; Holloway, T.M.; Lim, C.; McLeod, J.C.; McGlory, C.; Baker, S.K.; Phillips, S.M. Potato Protein Isolate Stimulates Muscle Protein Synthesis at Rest and with Resistance Exercise in Young Women. Nutrients 2020, 12, 1235. [CrossRef]

29. Howard, E.E.; Pasiakos, S.M.; Blesso, C.N.; Fussell, M.A.; Rodriguez, N.R. Divergent Roles of Inflammation in Skeletal Muscle Recovery from Injury. Front. Physiol. 2020, 11, 87. [CrossRef] 
30. Zeng, N.; D’Souza, R.F.; MacRae, C.L.; Figueiredo, V.C.; Pileggi, C.A.; Markworth, J.F.; Merry, T.L.; Cameron-Smith, D.; Mitchell, C.J. Daily protein supplementation attenuates immobilization-induced blunting of postabsorptive muscle mTORC1 activation in middle-aged men. Am. J. Physiol. Physiol. 2021, 320, C591-C601. [CrossRef]

31. Fry, C.S.; Johnson, D.L.; Ireland, M.L.; Noehren, B. ACL injury reduces satellite cell abundance and promotes fibrogenic cell expansion within skeletal muscle. J. Orthop. Res. 2016, 35, 1876-1885. [CrossRef] [PubMed]

32. Møller, A.B.; Vendelbo, M.H.; Schjerling, P.; Couppé, C.; Moller, N.; Kjær, M.; Hansen, M.; Jessen, N. Immobilization Decreases FOXO3a Phosphorylation and Increases Autophagy-Related Gene and Protein Expression in Human Skeletal Muscle. Front. Physiol. 2019, 10, 736. [CrossRef] [PubMed]

33. Greenhaff, P.L.; Karagounis, L.; Peirce, N.; Simpson, E.J.; Hazell, M.; Layfield, R.; Wackerhage, H.; Smith, K.; Atherton, P.; Selby, A.; et al. Disassociation between the effects of amino acids and insulin on signaling, ubiquitin ligases, and protein turnover in human muscle. Am. J. Physiol. Endocrinol. Metab. 2008, 295, E595-E604. [CrossRef] [PubMed] 